\title{
Sistemas de cultivo, sucessões de culturas, densidade do solo e sobrevivência de patógenos de solo
}

\author{
Eliane Divina de Toledo-Souza ${ }^{(1)}$, Pedro Marques da Silveira ${ }^{(2)}$, Murillo Lobo Junior(2) \\ e Adalberto Corrêa Café Filho(3)
}

(1)Universidade Federal de Goiás, Caixa Postal 131, CEP 74001-970 Goiânia, GO. E-mail: eliane.d.toledo@gmail.com (2)Embrapa Arroz e
Feijão, Caixa Postal 179, CEP 75375-000 Santo Antônio de Goiás, GO. E-mail: pmarques@cnpaf.embrapa.br, murillo@cnpaf.embrapa.br
(3)Universidade de Brasília, Departamento de Fitopatologia, CEP 70910-900 Brasília, DF. E-mail: cafefilh@unb.br

Resumo - O objetivo deste trabalho foi avaliar o efeito de sistemas de manejo do solo e de cultivos prévios ao plantio do feijoeiro (Phaseolus vulgaris L.) sobre a densidade do solo e as populações de Rhizoctonia spp. e de Fusarium spp. Os cultivos prévios incluíram as leguminosas: guandu-anão (Cajanus cajan), estilosantes (Stylosanthes guianensis cv. Mineirão) e crotalária (Crotalaria spectabilis); e as gramíneas: milheto (Pennisetum glaucum cv. BN-2), sorgo granífero (Sorghum bicolor cv. BR 304), capim-mombaça (Panicum maximum cv. Mombaça), braquiária (Brachiaria brizantha cv. Marandu) e milho (Zea mays) consorciado com braquiária. As culturas utilizadas no cultivo prévio foram semeadas nos verões de 2002, 2003 e 2004, e os plantios de feijoeiro, cultivar BRS Valente, foram realizados nos invernos subseqüentes de 2003, $2004 \mathrm{e}$ 2005, com irrigação por pivô central. Os restos culturais dos cultivos eram incorporados ao solo, no plantio convencional, e ficavam à superfície, no plantio direto. De modo geral, as maiores populações de Fusarium spp. e Rhizoctonia spp. e as maiores densidades de solo foram encontradas no solo cultivado em plantio direto. As maiores populações de Rhizoctonia spp. foram observadas em solos mais adensados. As leguminosas geralmente aumentaram populações desses patógenos e devem ser evitadas como culturas prévias ao cultivo do feijoeiro, em ambos os sistemas de cultivo. Plantios prévios de gramíneas, em geral, são supressores das populações de Rhizoctonia spp. e de Fusarium spp. no solo.

Termos para indexação: Fusarium, Rhizoctonia, fungo de solo, plantio convencional, plantio direto, podridão radicular.

\section{Cropping systems and previous crops on soil density and survival of soil-borne pathogens}

\begin{abstract}
The objective of this work was to evaluate the effect of cropping systems and crops cultivated previously to common beans (Phaseolus vulgaris L.) on soil density and soil populations of Rhizoctonia spp. and Fusarium spp. Previous crops included the following legumes: Cajanus cajan, Stylosanthes guianensis cv. Mineirão and Crotalaria spectabilis; and the following grasses: Pennisetum glaucum (cv. BN-2, millet), Sorghum bicolor (cv. BR 304), Panicum maximum cv. Mombaça, Brachiaria brizantha cv. Marandu and a consortium of corn (Zea mays) and B. brizantha. Previous crops were planted in Brazil summer seasons (wet) of 2002, 2003 e 2004, and bean crop (cv. BRS Valente) was planted in the correspondent subsequent winters (dry) of 2003, 2004 and 2005, irrigated by central pivot. Crop residues were incorporated to the soil, in conventional tillage, and kept on the surface, in no tillage management. In general, soil populations of Fusarium spp. and Rhizoctonia spp. were higher in no tillage cropping system. Higher populations of Rhizoctonia spp. were found in heavier soils. Legume crop residue increased soil populations of Rhizoctonia spp. and Fusarium spp. and, therefore, Leguminosae should be avoided as previous crops to common beans, in both cultivation systems. Generally, Gramineae previous crops are supressive to soil populations of Rhizoctonia spp. and Fusarium spp.
\end{abstract}

Index terms: Fusarium, Rhizoctonia, soil fungi, conventional cropping, zero tillage, root rot.

\section{Introdução}

No feijoeiro-comum (Phaseolus vulgaris L.), as doenças causadas por patógenos de solo constituem um complexo etiológico que reduz o estande e o vigor das plantas e é responsável pelas maiores perdas de produtividade, em áreas irrigadas do Centro-Sul do Brasil (Cardoso, 1992). As podridões radiculares 
constituintes desse complexo etiológico mais comumente encontradas nessas regiões são causadas por Fusarium solani (Mart.) Sacc. f. sp. phaseoli (Burkholder) (teleomorfo: Nectria haematococca Berk. \& Broome) e Rhizoctonia solani Kühn [teleomorfo: Thanatephorus cucumeris (A.B. Frank) Donk]. Esses dois patógenos ocorrem tanto isolados como em associação (Tomita et al., 1996).

A incorporação de matéria orgânica pode melhorar as características físicas e químicas do solo, aumentar a atividade e o tamanho da comunidade microbiana, e ainda ter efeito no controle de fitopatógenos (Fenile \& Sousa, 1999; Baptista et al., 2007).

Segundo Papavizas \& Davey (1961) e Hoitink et al. (1996), a atividade saprofítica de $R$. solani é suprimida por resíduos com alta relação $C$ :N. Entretanto, não se pode generalizar a correlação entre a relação $\mathrm{C}: \mathrm{N}$ da matéria orgânica e a severidade de doenças (Ferraz et al., 1999). O grau de decomposição dos resíduos vegetais também é importante na etiologia das doenças, já que resíduos com baixa relação $\mathrm{C}: \mathrm{N}$, quando frescos, podem propiciar a ocorrência de $R$. solani e podem ser supressivos ao sofrer decomposição (Chung et al., 1988).

A ação de compostos orgânicos na redução de doenças causadas por patógenos de solo é conhecida, e vários adubos verdes, resíduos culturais e outros resíduos orgânicos são usados na busca desse efeito (Hoitink et al., 1996). Esses resíduos são convertidos em compostos orgânicos via mineralização biológica e, além de seu efeito benéfico nas características físicas e químicas do solo, podem induzir supressividade e atuar no controle de doenças causadas por patógenos de solo (Hoitink \& Boehm, 1991).

$\mathrm{O}$ sistema de plantio direto $(\mathrm{PD})$ promove inúmeros benefícios ao solo, tais como: maior proteção contra o impacto direto das gotas de chuva, favorecimento da infiltração, redução da perda de água por escoamento superficial, e da perda do solo e nutrientes por erosão (Hernani et al., 1999). Além disso, propicia maior disponibilidade de água e nutrientes às plantas e melhora as condições físicas e químicas do solo, com o aumento da matéria orgânica (Crusciol \& Sorato, 2007).

A influência da cobertura orgânica no solo sobre fatores físicos, químicos e biológicos é fundamental no estabelecimento de condições favoráveis ou não ao desenvolvimento de doenças. Entretanto, o PD mal executado pode resultar em problemas fitossanitários às culturas de soja e de feijão, principalmente quando: o plantio é realizado com elevado teor de umidade no solo; não se obedece a um esquema racional de rotação de culturas; e o solo está compactado (Costamilan, 1999). A severidade da podridão causada por fusário, em feijoeiro, pode estar relacionada a fatores físicos, como a densidade do solo (Tomita et al., 1996; Café-Filho \& Lobo Júnior, 2000). Após aumentos de rendimento nos primeiros anos da implantação do PD, tem-se observado a redução paulatina do rendimento em feijão, no decorrer das safras, em razão do aumento da incidência e da severidade de doenças, entre outros fatores (Paula Júnior et al., 2004). Segundo Tormena et al. (1998), a compactação do solo tem sido uma ameaça à continuidade do PD.

O feijoeiro-comum tem sido cultivado em rotação ou sucessão, principalmente com milho, aveia-preta ou branca, soja, trigo, milheto, leguminosas forrageiras e diferentes tipos de sorgo (Balbino et al., 1996). Mais recentemente, foram preconizados, em áreas de lavoura, sistemas consorciados de culturas de grãos com forrageiras, na integração lavoura-pecuária, cognominado de Sistema Santa Fé (Kluthcouski et al., 2000). As palhadas de gramíneas são excelentes fornecedoras de nutrientes às culturas sucessoras, graças ao elevado acúmulo dos nutrientes na matéria seca e às suas altas taxas de mineralização (Boer et al., 2007; Torres et al., 2008). Braz et al. (2004) verificaram que o milheto, a braquiária e o capim-mombaça têm capacidade de acumular grande quantidade de nutrientes. Contudo, são poucos os estudos acerca da influência dos resíduos culturais na população de patógenos do solo.

O objetivo deste trabalho foi avaliar o efeito de sistemas de plantio, de cultivos prévios ao plantio do feijoeiro, com gramíneas e leguminosas sobre a densidade do solo e as populações de Rhizoctonia spp. e Fusarium spp.

\section{Material e Métodos}

Os experimentos foram realizados em três safras consecutivas (2002/2003, 2003/2004 e 2004/2005), em Latossolo Vermelho-Escuro distrófico (58\% de argila, $13 \%$ de silte e $29 \%$ de areia), na Fazenda Capivara, da Embrapa Arroz e Feijão, em Santo Antônio de Goiás ( $16^{\circ} 28^{\prime} \mathrm{S}, 49^{\circ} 17^{\prime} \mathrm{W}$ e a $823 \mathrm{~m}$ de altitude).

$\mathrm{O}$ experimento foi instalado em faixas (plantio direto ou convencional), em delineamento de blocos 
ao acaso, com quatro repetições (Zimmermann, 2004). Cada bloco foi formado de oito parcelas de $80 \mathrm{~m}^{2}$ (20x4 m). No verão (12/2002, 11/2003 e 12/2004), foram semeadas, em cada parcela, as seguintes espécies: crotalária (Crotalaria spectabilis Roth.), guandu-anão [Cajanus cajan (L.) Millsp.], estilosantes [Stylosanthes guianensis (Aublet) Sw. var. vulgaris] cv. Mineirão, milheto [Pennisetum glaucum (L.) R. Br.] cv. BN-2, sorgo granífero [Sorghum bicolor (L.) Moench] cv. BR 304, capim-mombaça (Panicum maximum Jacq.) cv. Mombaça, braquiária [Brachiaria brizantha (A. Rich.) Stapf] cv. Marandu, e milho (Zea mays L.) consorciado com braquiária (B. brizantha cv. Marandu) (sistema Santa Fé). As culturas foram trituradas com triturador de palhada horizontal, entre 130 e 150 dias após a semeadura (DAS, 6/2003, 3/2004 e 4/2005). O milho e o sorgo foram colhidos antes da trituração dos restos culturais. Cada parcela foi dividida em duas faixas (10x4 m). Após o corte das culturas para incorporação dos resíduos vegetais, foram realizadas duas gradagens na faixa relativa ao plantio convencional (PC); na relativa ao plantio direto $(\mathrm{PD})$, o resíduo foi deixado na superfície do solo.

A semeadura do feijoeiro foi realizada no inverno (7/2003, 6/2004 e 6/2005), 60 dias após o corte das espécies de cobertura. Aproximadamente 15 dias antes da semeadura do feijão, foram aplicados $5 \mathrm{~L} \mathrm{ha}^{-1}$ do herbicida glifosato. A semeadura da cultivar BRS Valente - grupo preto, porte arbustivo e crescimento indeterminado (tipo III) - foi mecanizada, em espaçamento de $45 \mathrm{~cm}$, com 18 sementes por metro. Na adubação de plantio, utilizaram-se $400 \mathrm{~kg} \mathrm{ha}^{-1}$ das fórmulas 4-30-16 + Zn (safra 2003) e 5-25-15 + Zn (safras 2004 e 2005). Foram efetuadas duas adubações de cobertura, com $30 \mathrm{~kg} \mathrm{ha}^{-1}$ de N, por aplicação, aos 20 e 40 DAS. Aos 30 DAS, foram aplicados $0,25 \mathrm{~L} \mathrm{ha}^{-1}$ de fomesafen e 1,25 $\mathrm{L} \mathrm{ha}^{-1}$ de fluazifop-p-butil. As irrigações foram realizadas por pivô central, quando a média das leituras do potencial de água no solo, de três tensiômetros instalados na área a $0,15 \mathrm{~m}$ de profundidade, situava-se no intervalo entre -0,03 e -0,04 MPa (Silveira et al., 2001).

As análises estatísticas foram realizadas por safra de cultivo e conjuntamente, nas populações de Fusarium spp. (PF) e nas de Rhizoctonia spp. (PR), com o auxílio do SISVAR (Ferreira, 2003). Para a comparação das médias, foi utilizado o teste de Tukey, a 5\% de probabilidade. Realizaram-se, ainda, análises de correlações entre as variáveis massa da matéria seca dos cultivos prévios, densidade do solo, PF e PR.
Para a determinação da matéria seca adicionada ao solo pelos cultivos prévios ao do feijoeiro, o resíduo orgânico das culturas foi coletado sobre a área de $1 \mathrm{~m}^{2}$, após a trituração. O material coletado foi secado ao ar livre, até massa constante e, então, pesado.

A amostragem para determinação da densidade do solo (Ds) foi feita pela introdução, na camada de 5-10 cm, do conjunto de cilindro de Uhland com volume de $98,17 \mathrm{~cm}^{3}$. A massa foi determinada após a secagem do material em estufa a $105^{\circ} \mathrm{C}$, durante 24 horas (Blake \& Hartge, 1986).

Amostras compostas foram coletadas na linha da semeadura, a $0-10 \mathrm{~cm}$ de profundidade, aos 34 DAS, para a estimativa da população de propágulos no solo. A população total das espécies de Fusarium foi estimada pela diluição de $10 \mathrm{~g}$ de solo em água estéril até a razão 1:100 (Johnson \& Curl, 1972). Um mililitro da solução do solo (1:100) foi plaqueado, em meio semi-seletivo de Nash \& Snyder (1962), com cinco repetições por tratamento. A estimativa do número de propágulos de Fusarium spp. por grama de solo foi obtida pela fórmula: $\mathrm{NP}=\mathrm{NCx} 100$, em que NP é o número de propágulos por grama de solo, e NC é o número médio de colônias por placa. Não foi realizada a estimativa de população de cada espécie de Fusarium. Para a análise de variância, os dados foram transformados por $(\mathrm{x}+1)^{0,5}$.

Utilizou-se o método de extração e plaqueamento do resíduo orgânico do solo (Weinhold, 1977) para a quantificação da população de $R$. solani. Foram transferidos nove fragmentos de resíduo orgânico por placa de ágar-água, com cinco repetições. As leituras do número de colônias por placa, tanto para Fusarium spp. quanto para Rhizoctonia spp., foram realizadas cinco dias após o plaqueamento a $25^{\circ} \mathrm{C}$. A percentagem dos resíduos orgânicos colonizados (ROC) foi obtida pela fórmula $\% \mathrm{ROC}=\mathrm{NCx} 100 / 9$, em que NC é o número médio de colônias por placa. Para a análise de variância, os dados foram transformados por $(\mathrm{x}+1)^{0,5}$.

\section{Resultados e Discussão}

Quanto à população de Fusarium spp., a análise conjunta das safras mostrou interações significativas entre safras, sistemas de plantio e culturas prévias. De modo geral, foram encontradas maiores populações sob o sistema plantio direto (PD), com exceção do 
cultivo prévio com $B$. brizantha, nas safras 2003 e 2005 , em que a população foi maior no plantio convencional (PC) (Figura 1). Segundo Costa \& Rava (2003), há redução do potencial de inóculo de alguns patógenos de solo e tendência de obtenção de maiores rendimentos de feijão, quando braquiárias são utilizadas como fonte de cobertura morta, no PD. A sucessão ou rotação com braquiária é uma boa alternativa para se viabilizar a continuidade do PD em áreas afetadas por patógenos de solo, uma vez que os resultados mostraram tendência
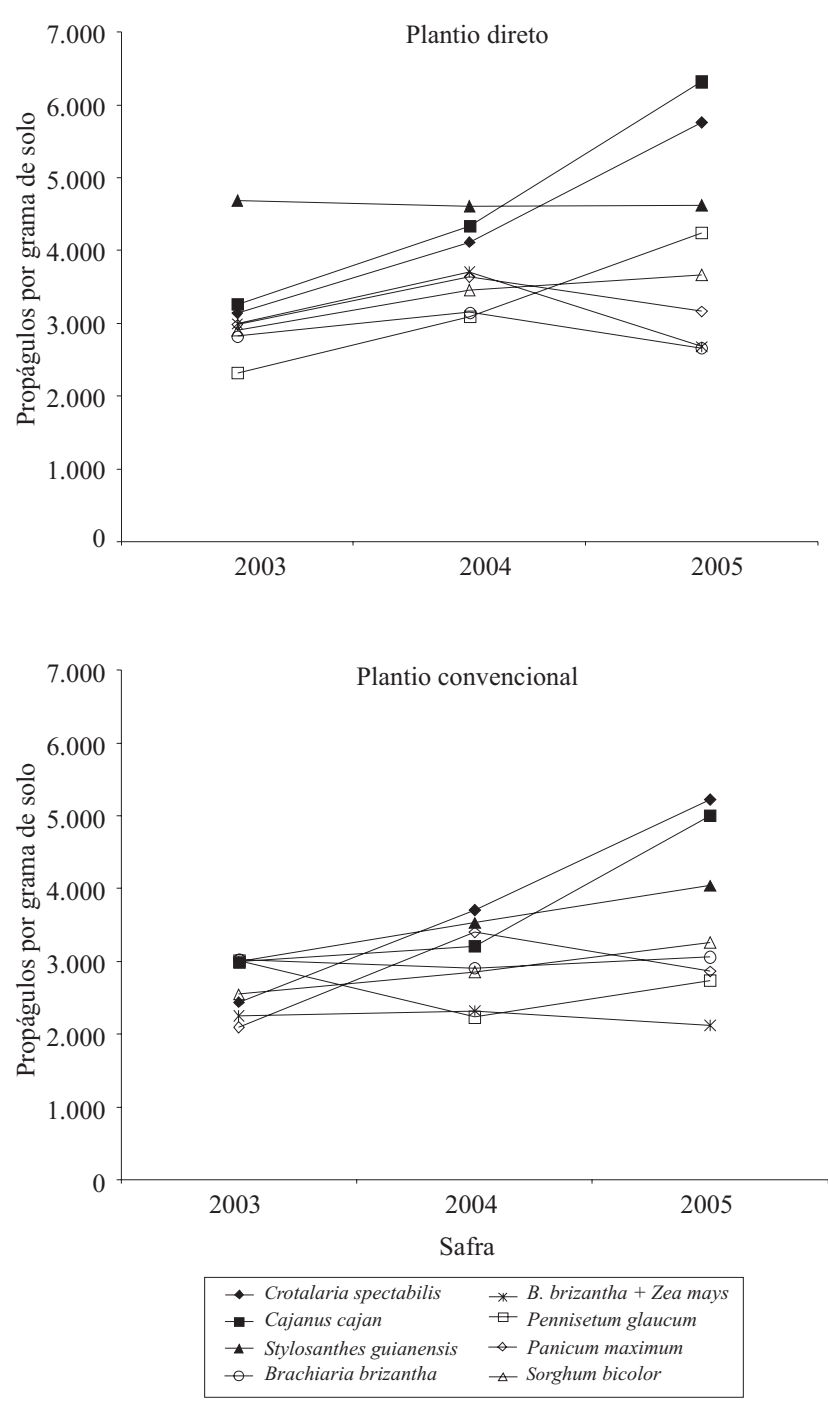

Figura 1. População de Fusarium spp., em solos cultivados com feijão (Phaseolus vulgaris), correspondentes aos cultivos prévios nos sistemas plantio direto e plantio convencional, nas safras 2003, 2004 e 2005. de menor número de propágulos com uso deste cultivo prévio, principalmente em 2003 e 2005 (Figura 1).

No PD, foram observados, ao longo das safras, aumentos sucessivos na população de Fusarium, com a utilização das culturas prévias $C$. spectabilis, $C$. cajan e P. glaucum. No PC, aumentos ocorreram nos cultivos prévios de C. spectabilis, C. cajan e $S$. guianensis (Figura 1). Resíduos de leguminosas favoreceram o aumento da população de Fusarium spp. (PF), independentemente do sistema de cultivo. Hall \& Phillips (1992) relataram que a dinâmica da população de $F$. solani f. sp. phaseoli, no solo, depende do efeito de seqüências de culturas e da chuva. Esses autores relataram que, em parcelas não cultivadas com o feijoeiro, o número de unidades formadoras de colônia de $F$. solani f. sp. phaseoli por grama de solo foi menor que 50, enquanto nas parcelas cultivadas anualmente $\mathrm{e}$ a cada três anos (em rotação com soja e milho) foi de 660 e 475 , respectivamente.

A análise individual das safras mostrou, em 2003, interação significativa entre sistemas de plantio e culturas prévias, e não-significativa nas safras 2004 e 2005, para a PF (Tabela 1). Na safra 2003, no PD, maiores populações foram observadas no cultivo com $S$. guianensis e, no PC, com o cultivo de B. brizantha, que, no entanto, diferiu significativamente apenas do cultivo com P. maximum. Na safra de 2004, foram observadas diferenças estatísticas entre sistemas de plantio e entre culturas prévias. Maiores populações foram observadas no PD (3.763 e 3.019 propágulos por grama de solo, respectivamente para PD e PC).

Tabela 1. População de Fusarium spp. (propágulos por grama) em solos cultivados com feijão (Phaseolus vulgaris), correspondentes aos cultivos prévios nos sistemas plantio convencional (PC) e plantio direto (PD), nas safras 2003, 2004 e $2005^{(1)}$.

\begin{tabular}{|c|c|c|c|c|}
\hline \multirow[t]{2}{*}{ Cultivo prévio } & \multicolumn{2}{|c|}{2003} & \multirow[t]{2}{*}{2004} & \multirow[t]{2}{*}{2005} \\
\hline & $\mathrm{PC}$ & $\mathrm{PD}$ & & \\
\hline C. spectabilis & $2.440 \mathrm{ab}$ & $3.135 \mathrm{a}$ & $3.910 \mathrm{~cd}$ & $5.490 \mathrm{c}$ \\
\hline C. cajan & $2.995 \mathrm{ab}$ & $3.265 \mathrm{a}$ & $3.770 \mathrm{bcd}$ & $5.660 \mathrm{c}$ \\
\hline S. guianensis & $2.995 \mathrm{ab}$ & $4.685 b$ & $4.068 \mathrm{~d}$ & $4.330 \mathrm{bc}$ \\
\hline B. brizantha & $3.025 b$ & $2.820 \mathrm{a}$ & $3.028 \mathrm{ab}$ & $2.860 \mathrm{ab}$ \\
\hline B. brizantha $+Z$. mays & $2.255 \mathrm{ab}$ & $2.995 \mathrm{a}$ & $3.013 \mathrm{ab}$ & $2.400 \mathrm{a}$ \\
\hline P. glaucum & $3.015 \mathrm{ab}$ & $2.320 \mathrm{a}$ & $2.663 a$ & $3.490 \mathrm{ab}$ \\
\hline P. maximum & $2.095 \mathrm{a}$ & $2.980 \mathrm{a}$ & $3.518 \mathrm{bcd}$ & $3.010 \mathrm{ab}$ \\
\hline S. bicolor & $2.545 \mathrm{ab}$ & $2.900 \mathrm{a}$ & $3.158 \mathrm{abc}$ & $3.460 \mathrm{ab}$ \\
\hline CV (\%) & & & 16,73 & 30,37 \\
\hline
\end{tabular}

${ }^{(1)}$ Médias seguidas de letras iguais, nas colunas, não diferem entre si pelo teste de Tukey, a 5\% de probabilidade. 
O cultivo prévio com $S$. guianensis apresentou, também, a maior PF. Na safra de 2005, foram observadas diferenças estatísticas apenas entre os cultivos prévios. Observaram-se maiores populações no solo, quando o feijoeiro foi precedido pelas leguminosas, que não diferiram entre si. A menor PF foi observada com o cultivo prévio $B$. brizantha consorciado com $Z$. mays.

Quanto à população de Rhizoctonia spp.(PR), a análise conjunta das safras mostrou interações significativas entre safras, sistemas de plantio e cultivos prévios. As maiores PR foram observadas na safra 2003 (com exceção do cultivo com B. brizantha eZ. mays)(Figura 2).
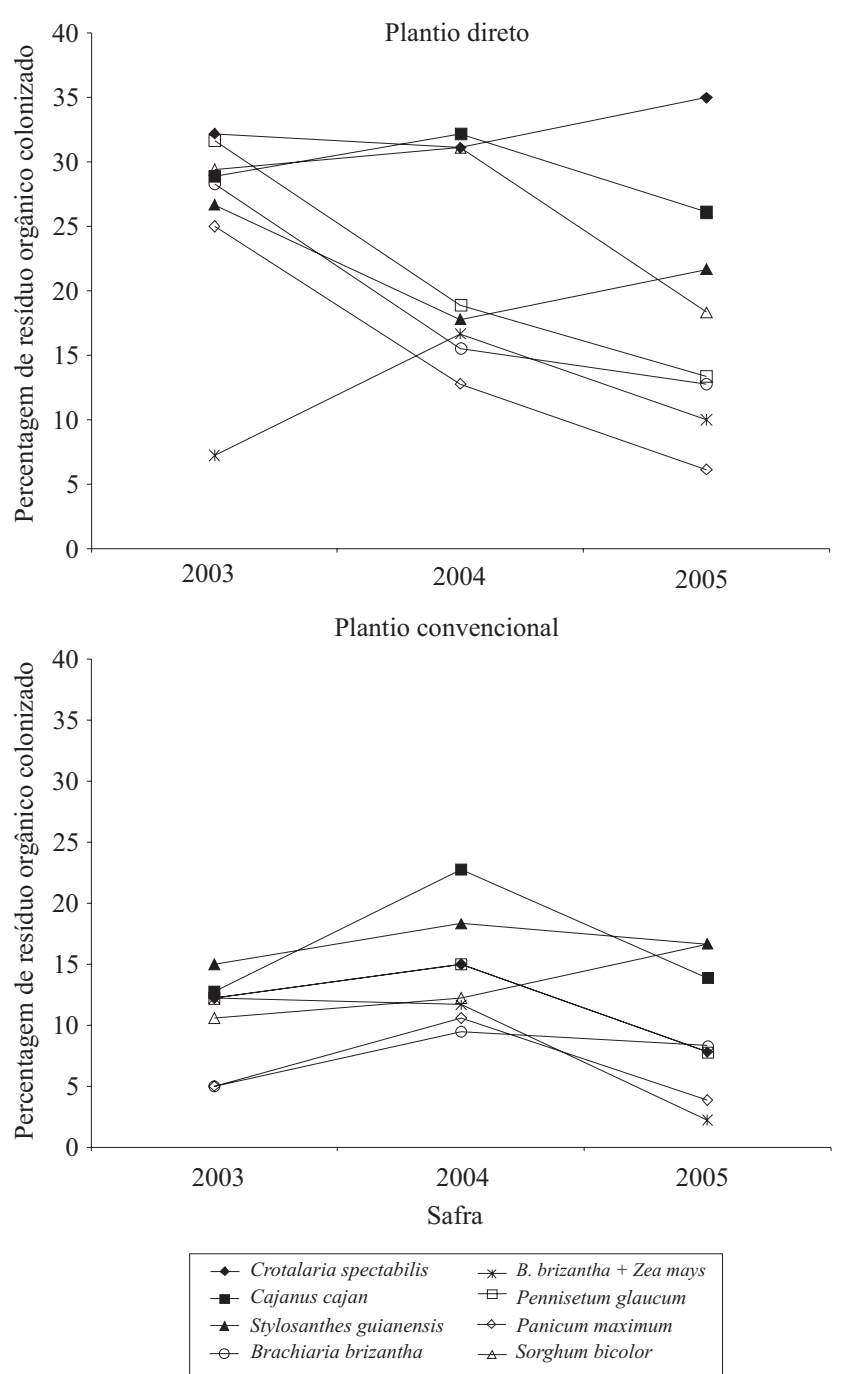

Figura 2. População de Rhizoctonia spp., em percentagem do resíduo orgânico colonizado, em solos cultivados com feijão (Phaseolus vulgaris), correspondentes aos cultivos prévios nos sistemas plantio direto e plantio convencional, nas safras 2003, 2004 e 2005.
No PD, houve redução gradativa da PR, ao longo das safras, nos cultivos com B. brizantha e P. maximum, enquanto essas populações se mantiveram altas em cultivos com $C$. cajan e C. spectabilis. No plantio convencional, a PR manteve-se constante no decorrer das safras, em todos os cultivos prévios. A PR foi maior no PD, com exceção do cultivo com $S$. guianensis, na safra 2004, quando foi maior no PC.

De modo geral, os experimentos demonstraram maior sobrevivência de ambos os patógenos em solos sob PD, tanto com resíduos de gramíneas quanto com leguminosas. Esses resultados corroboram os de Hoitink et al. (1996), que constataram maior atividade saprofítica de $R$. solani, em solo sem a incorporação de resíduos orgânicos do que com incorporação. Segundo Zambolim et al. (2000), isso ocorre, possivelmente, pelo fato de os resíduos deixados na superfície do solo decomporem-se mais lentamente do que os resíduos incorporados, o que propiciaria maior disponibilidade de tempo para aumento da população de patógenos.

A análise individual das safras não mostrou, em 2003 e 2004, interações significativas entre sistemas de plantio e cultivos prévios, para PR (Tabela 2). Na safra 2003, foram observadas diferenças entre sistemas de plantio e entre cultivos prévios. As maiores populações foram verificadas no PD $(25,7$ e $10,6 \%$ de resíduo orgânico colonizado, respectivamente no PD e PC). Com exceção do P. glaucum, as menores populações foram observadas nas gramíneas; contudo, apenas o cultivo consorciado $B$. brizantha e Zea mays diferiu significativamente das leguminosas. Na safra 2004,

Tabela 2. População de Rhizoctonia spp., em percentagem de resíduo orgânico colonizado, em solos cultivados com feijão (Phaseolus vulgaris), correspondentes aos cultivos prévios nos sistemas plantio convencional (PC) e plantio direto (PD), nas safras 2003, 2004 e $2005^{(1)}$.

\begin{tabular}{lclcc}
\hline Cultivo prévio & 2003 & 2004 & \multicolumn{2}{c}{2005} \\
\cline { 4 - 5 } & & & $\mathrm{PC}$ & $\mathrm{PD}$ \\
\hline C. spectabilis & $22,2 \mathrm{~b}$ & $23,1 \mathrm{bc}$ & $7,8 \mathrm{ab}$ & $35,0 \mathrm{~d}$ \\
C. cajan & $20,8 \mathrm{~b}$ & $27,5 \mathrm{c}$ & $13,9 \mathrm{ab}$ & $26,1 \mathrm{~cd}$ \\
S. guianensis & $20,8 \mathrm{~b}$ & $18,1 \mathrm{abc}$ & $16,7 \mathrm{~b}$ & $21,7 \mathrm{bcd}$ \\
B. brizantha & $16,7 \mathrm{ab}$ & $12,5 \mathrm{a}$ & $8,3 \mathrm{ab}$ & $12,8 \mathrm{abc}$ \\
B. brizantha + Z. mays & $9,7 \mathrm{a}$ & $14,2 \mathrm{ab}$ & $2,2 \mathrm{a}$ & $10,0 \mathrm{ab}$ \\
$P$. glaucum & $21,9 \mathrm{~b}$ & $16,9 \mathrm{abc}$ & $7,8 \mathrm{ab}$ & $13,3 \mathrm{abc}$ \\
$P$. maximum & $15,0 \mathrm{ab}$ & $11,7 \mathrm{a}$ & $3,9 \mathrm{ab}$ & $6,1 \mathrm{a}$ \\
S. bicolor & $20,0 \mathrm{ab}$ & $21,7 \mathrm{abc}$ & $16,7 \mathrm{~b}$ & $18,3 \mathrm{abc}$ \\
\hline CV $(\%)$ & 28,40 & 27,15 & \multicolumn{2}{c}{29,96} \\
\hline
\end{tabular}

${ }^{(1)}$ Médias seguidas de letras iguais, nas colunas, não diferem entre si pelo teste de Tukey, a 5\% de probabilidade. 
houve diferença apenas entre os cultivos prévios. Maiores populações foram observadas no cultivo prévio com $C$. cajan, que diferiu significativamente dos cultivos com $P$. maximum e $B$. brizantha, solteira ou consorciada. Na safra de 2005, no PD, a maior PR foi observada no cultivo com $C$. spectabilis, que não diferiu significativamente das demais leguminosas, mas sim de todas as gramíneas.

As massas dematéria seca(MMS) das culturas prévias ao feijoeiro apresentaram diferenças significativas, nas três safras (Tabela 3). Na safra 2003, a menor MMS foi observada em S. bicolor, bastante inferior às demais gramíneas e semelhante apenas ao C. cajan. Na safra 2004, os menores valores de MMS foram também foram observados em $S$. bicolor, com diferenças significativas, no entanto, apenas de $B$. brizantha e P. maximum. Na safra de 2005 , a menor MMS foi observada novamente em $S$. bicolor, mais uma vez com diferenças significativas apenas para $B$. brizantha e $P$. maximum. De modo geral, $P$. maximum produziu as maiores MMS.

Quando as MMS de gramíneas e leguminosas foram analisadas separadamente, observaram-se, nas safras 2004 e 2005, correlações significativas positivas, entre PR e MMS de leguminosas ( $r=0,4242$ e 0,4453, respectivamente para cada safra), e negativas, entre PR e MMS de gramíneas $(\mathrm{r}=-0,4681$ e $-0,3090$, respectivamente para as safras 2004 e 2005). Essas correlações indicam que resíduos de leguminosas favorecem a população de Rhizoctonia spp. no solo, enquanto resíduos de gramíneas os suprimem. Provavelmente, um dos fatores que contribuiu para esse resultado tenha sido a relação $\mathrm{C}: \mathrm{N}$, que normalmente é maior nas gramíneas e menor nas leguminosas.
Segundo Papavizas \& Davey (1961), R. solani tem sua atividade saprofítica no solo suprimida por resíduos com alta relação C:N. Segundo Fenile \& Sousa (1999), resíduos com baixa relação C:N, como torta de mamona, favorecem o desenvolvimento de $R$. solani $\mathrm{e}$ aumentam o seu potencial de inóculo no solo.

Não houve interação significativa entre sistemas de plantio e cultivos prévios, em nenhuma das safras, quanto à densidade do solo (DS). Houve diferença apenas entre sistemas de plantio, nas safras 2003 e 2005 (Tabela 3). Nessas duas safras, a DS foi maior no PD (1,49 e $1,30 \mathrm{~g} \mathrm{~cm}^{-3}$, respectivamente) e menor no PC (1,38 e $1,18 \mathrm{~g} \mathrm{~cm}^{-3}$, respectivamente). A avaliação da DS tem sido o método mais usado para identificar camadas compactadas e, de acordo com Dias Júnior (2000), é um importante atributo físico dos solos, por fornecer indicações a respeito do estado de sua conservação, além de ser uma das primeiras propriedades a ser alterada pelos diferentes usos. Segundo Sá (2000), alguns produtores da Região Sul do Brasil indicam a compactação no sistema de plantio direto como a principal causa de baixos rendimentos de culturas, em razão da elevada resistência física no desenvolvimento de raízes. Na safra 2004, foram observadas diferenças apenas entre os cultivos prévios: a DS foi maior no cultivo com S. bicolor e menor com C. cajan.

Nas safras 2003 e 2004, foram observadas correlações positivas entre a população de Rhizoctonia e a DS (Tabela 4), indicativo de que altas DS favorecem este patógeno. É provável que a compactação seja condição favorável à ocorrência da doença, o que está de acordo com o já relatado por alguns autores (Tomita et al., 1996; Costamilan, 1999; Café-Filho \& Lobo Júnior, 2000). Como conseqüência do aumento na DS, esse patógeno tem sua a população aumentada.

Tabela 3. Massa da matéria seca de culturas prévias e densidade do solo, em cultivo com o feijoeiro, nos sistemas plantio direto (PD) e plantio convencional (PC) ${ }^{(1)}$.

\begin{tabular}{|c|c|c|c|c|c|c|c|c|}
\hline \multirow[t]{3}{*}{ Cultura } & \multicolumn{3}{|c|}{ Massa de matéria seca $\left(\mathrm{kg} \mathrm{ha}^{-1}\right)$} & \multicolumn{5}{|c|}{ Densidade do solo $\left(\mathrm{g} \mathrm{cm}^{-3}\right)$} \\
\hline & \multirow[t]{2}{*}{2003} & \multirow[t]{2}{*}{2004} & \multirow[t]{2}{*}{2005} & \multicolumn{2}{|c|}{2003} & \multirow[t]{2}{*}{2004} & \multicolumn{2}{|c|}{2005} \\
\hline & & & & $\mathrm{PD}$ & $\mathrm{PC}$ & & $\mathrm{PD}$ & $\mathrm{PC}$ \\
\hline C. spectabilis & $4.963 \mathrm{abc}$ & $8.600 \mathrm{ab}$ & $9.687 \mathrm{abc}$ & 1,54 & 1,37 & $1,40 \mathrm{ab}$ & 1,36 & 1,24 \\
\hline C. cajan & $3.733 \mathrm{ab}$ & $8.088 \mathrm{a}$ & $9.237 \mathrm{abc}$ & 1,47 & 1,39 & $1,33 \mathrm{a}$ & 1,26 & 1,21 \\
\hline S. guianensis & $10.338 \mathrm{~d}$ & $5.750 \mathrm{a}$ & $8.725 \mathrm{ab}$ & 1,43 & 1,40 & $1,36 a b$ & 1,31 & 1,21 \\
\hline B. brizantha & $14.968 \mathrm{e}$ & $13.925 \mathrm{bc}$ & $13.750 \mathrm{bc}$ & 1,51 & 1,37 & $1,41 \mathrm{ab}$ & 1,35 & 1,15 \\
\hline B. brizantha + Z. mays & $8.783 \mathrm{~cd}$ & $7.988 \mathrm{a}$ & $10.612 \mathrm{abc}$ & 1,51 & 1,34 & $1,36 \mathrm{ab}$ & 1,29 & 1,11 \\
\hline P. glaucum & $7.615 \mathrm{bcd}$ & $10.588 \mathrm{abc}$ & $7.525 \mathrm{ab}$ & 1,49 & 1,37 & $1,39 \mathrm{ab}$ & 1,33 & 1,21 \\
\hline P. maximum & $16.350 \mathrm{e}$ & $15.238 \mathrm{c}$ & $16.100 \mathrm{c}$ & 1,48 & 1,42 & $1,36 a b$ & 1,26 & 1,20 \\
\hline S. bicolor & $2.398 \mathrm{a}$ & $4.812 \mathrm{a}$ & $5.650 \mathrm{a}$ & 1,53 & 1,40 & $1,48 \mathrm{~b}$ & 1,28 & 1,17 \\
\hline CV (\%) & 21,02 & 26,08 & 28,56 & & & 6,30 & & \\
\hline
\end{tabular}

${ }^{(1)}$ Médias seguidas de letras iguais, nas colunas, não diferem entre si pelo teste de Tukey, a 5\% de probabilidade. 
Tabela 4. Coeficientes de correlação de Pearson, entre a massa da matéria seca (MMS, $\left.\mathrm{kg} \mathrm{ha}^{-1}\right)$ das culturas prévias ao feijoeiro, a população de Rhizoctonia spp. (PR, \% do resíduo orgânico colonizado), a população de Fusarium spp. (PF, nº de propágulos por grama de solo) e a densidade do solo (DS, $\mathrm{g} \mathrm{cm}^{-3}$ ), nas safras 2003, 2004 e 2005.

\begin{tabular}{|c|c|c|c|c|c|c|c|c|c|}
\hline \multirow[t]{2}{*}{ Variável } & \multicolumn{3}{|c|}{ Safra 2003} & \multicolumn{3}{|c|}{ Safra 2004} & \multicolumn{3}{|c|}{ Safra 2005} \\
\hline & PR & PF & DS & PR & PF & DS & PR & PF & DS \\
\hline MMS & $-0,1400$ & 0,0183 & 0,0770 & $-0,2327$ & $-0,0304$ & $-0,1242$ & $-0,1165$ & $-0,1428$ & $-0,0597$ \\
\hline PR & & 0,1286 & 0,2635 & & 0,1790 & $0,2474 *$ & & $0,3971^{*}$ & 0,1875 \\
\hline PF & & & 0,1303 & & & $-0,0168$ & & & 0,2089 \\
\hline
\end{tabular}

*Significativo pelo teste $\mathrm{t}$, a $5 \%$ de probabilidade.

\section{Conclusões}

1. O sistema plantio direto favorece o aumento da população de Rhizoctonia spp. e de Fusarium spp. no solo.

2. O sistema plantio direto apresenta solos mais adensados, e o aumento na população de Rhizoctonia spp. deve ser esperado com o aumento na densidade do solo.

3. O plantio de leguminosas como culturas prévias, no verão, deve ser evitado para produção de feijoeiro irrigado no inverno, tanto no sistema convencional como no plantio direto.

4. Plantios prévios de gramíneas, em geral, são supressores das populações de Rhizoctonia spp. e de Fusarium spp. em áreas infestadas; plantios prévios de leguminosas, em geral, favorecem o aumento nas populações desses patógenos.

\section{Agradecimentos}

À Coordenação de Aperfeiçoamento de Pessoal de Nível Superior e ao Conselho Nacional de Desenvolvimento Científico e Tecnológico, por concessão de bolsas.

\section{Referências}

BALBINO, L.C.; MOREIRA, J.A.A.; SILVA, J.G. da; OLIVEIRA, E.F. de; OLIVEIRA, I.P. de. Plantio Direto. In: ARAÚJO, R.S.; RAVA, C.A.; STONE, L.F.; ZIMMERMANN, M.J. de O. (Coord.). Cultura do feijoeiro-comum no Brasil. Piracicaba: Potafos, 1996. p.301-352.

BAPTISTA, M.J.; REIS JUNIOR, F.B. dos; XAVIER, G.R.; ALCÂNTARA, C. de; OLIVEIRA, A.R. de; SOUZA, R.B.; LOPES, C.A. Eficiência da solarização e biofumigação do solo no controle da murcha-bacteriana do tomateiro no campo. Pesquisa Agropecuária Brasileira, v.42, p.933-938, 2007.

BLAKE, G.R.; HARTGE, K.H. Bulk density. In: KLUTE, A. (Ed.). Methods of soil analysis: physical and mineralogical methods. Madison: ASA, 1986. p.363-375.
BOER, C.A.; ASSIS, R.L. de; SILVA, G.P.; BRAZ, A.J.B.P.; BARROSO, A.L. de L.; CARGNELUTTI FILHO, A.; PIRES, F.R. Ciclagem de nutrientes por plantas de cobertura na entressafra em um solo de cerrado. Pesquisa Agropecuária Brasileira, v.42, p.1269-1276, 2007.

BRAZ, A.J.B.P.; SILVEIRA, P.M. da; KLIEMANN, H.J.; ZIMMERMANN, F.J.P. Acumulação de nutrientes em folha de milheto e dos capins braquiária e mombaça. Pesquisa Agropecuária Tropical, v.34, p.83-87, 2004.

CAFÉ-FILHO, A.C.; LOBO-JÚNIOR, M. Manejo de fatores físicos e culturais para controle de patógenos de solo. Revisão Anual de Patologia de Plantas, v.8, p.267-301, 2000.

CARDOSO, J.E. Controle de patógenos de solo na cultura do feijão. In: SEMINÁRIO SOBRE PRAGAS E DOENÇAS NA CULTURA DO FEIJOEIRO, 4., 1991, Campinas. Anais. Campinas: IAC, 1992. p.45-50.

CHUNG, Y.R.; HOITINK, H.A.J.; DICK, W.A.; HERR, L.J. Effects of organic matter decomposition level and cellulose amendment on the inoculum potential of Rhizoctonia solani in hardwood bark media. Phytopathology, v.78, p.836-840, 1988.

COSTA, J.L. da S.; RAVA, C.A. Influência da braquiária no manejo de doenças do feijoeiro com origem no solo. In: KLUTHCOUSKI, J.; STONE, L.F.; AIDAR, H. (Ed.). Integração lavourapecuária. Santo Antônio de Goiás: Embrapa Arroz e Feijão, 2003. p.523-533.

COSTAMILAN, L.M. O sistema plantio direto e as doenças de soja e de feijão na Região Sul do Brasil. Passo Fundo: Embrapa Trigo, 1999. 9p. (Embrapa Trigo. Documentos Online, 1).

CRUSCIOL, C.A.C.; SORATTO, R.P. Nutrição e produtividade do amendoim em sucessão ao cultivo de plantas de cobertura no sistema plantio direto. Pesquisa Agropecuária Brasileira, v.42, p.1553-1560, 2007.

DHINGRA, O.D.; COELHO NETO, R.A. Reservoir and non-reservoir hosts of bean-wilt pathogen, Fusarium oxysporum f. sp. phaseoli. Journal of Phytopathology, v.149, p.463-467, 2001.

DIAS JÚNIOR, M.S. Compactação do solo. In: NOVAIS, R.F.; ALVAREZ VENEGAS, V.H.; SHAEFER, C.E.G.R. Tópicos em ciência do solo. Viçosa: SBCS, 2000. p.55-94.

FENILE, R.C.; SOUSA, N.L. de. Efeitos de materiais orgânicos e da umidade do solo na patogenicidade de Rhizoctonia solani Kühn GA-4 HGI ao feijoeiro. Pesquisa Agropecuária Brasileira, v.34, p.1959-1967, 1999. 
FERRAZ, L.C.L.; CAFÉ-FILHO, A.C.; NASSER, L.C.B.; AZEVEDO, J. Effects of soil moisture, organic matter and grass mulching on the carpogenic germination of Sclerotia and infection of bean by Sclerotinia sclerotiorum. Plant Pathology, v.48, p.77-82, 1999.

FERREIRA, D.F. Programa de análises estatísticas (Statistical Analysis Software) e planejamento de experimentos. Lavras: UFLA, 2003.

HALL, R.; PHILLIPS, L.G. Effects of crop sequence and rainfall on population dynamics of Fusarium solani f.sp. phaseoli in soil. Canadian Journal of Botany, v.70, p.2005-2008, 1992.

HERNANI, L.C.; KURIHARA, C.H.; SILVA, W.M. da. Sistema de manejo de solo e perdas de nutrientes e matéria orgânica por erosão. Revista Brasileira de Ciência do Solo, v.23, p.145-154, 1999.

HOITINK, H.A.J.; BOEHM, M.J. Interactions between organic matter decomposition level, biocontrol agents and plant pathogens in soil-borne disease. In: REUNIÃO BRASILEIRA SOBRE CONTROLE BIOLÓGICO DE DOENÇAS DE PLANTAS, 4., 1991, Campinas. Anais. Campinas: Emopi, 1991. p.63-77.

HOITINK, H.A.J.; MADDEN, L.V.; BOEHM, M.J. Relationships among organic matter decomposition level, microbial species diversity, and soilborne disease severity. In: HALL, R. (Ed.). Principles and practice of managing soilborne plant pathogens. St. Paul: APS Press, 1996. p.237-249.

JOHNSON, L.F.; CURL, E.A. Methods for research on the ecology of soil-borne plant pathogens. Minneapolis: Burgess Publishing, 1972. 178p

KLUTHCOUSKI, J.; COBUCCI, T.; AIDAR, H.; YOKOYAMA, L.P.; OLIVEIRA, I.P. de; COSTA, J.L. da S.; SILVA, J.G. da; VILELA, L.; BARCELLOS, A. de O.; MAGNABOSCO, C. de U. Sistema Santa Fé: tecnologia Embrapa: integração lavoura-pecuária pelo consórcio de culturas anuais com forrageiras, em áreas de lavoura, nos sistemas direto e convencional. Santo Antônio de Goiás: Embrapa Arroz e Feijão, 2000. 28p. (Embrapa Arroz e Feijão. Circular Técnica, 38).
NASH, S.M.; SNYDER, W.C. Quantitative estimations by plate counts of propagules of the bean root rot Fusarium in field soils. Phytopathology, v.52, p.567-572, 1962.

PAPAVIZAS, G.C.; DAVEY, C.B. Saprophytic behaviour of Rhizoctonia in soil. Phytopathology, v.51, p.693-699, 1961.

PAULA JÚNIOR, T.J. de; VIEIRA, R.F.; ZAMBOLIM, L. Manejo integrado de doenças do feijoeiro. Informe Agropecuário, v.25, p.99-112, 2004.

SÁ, J.C.M. A intimidade do processo. Por que não lavrar nem gradear o solo? Revista Plantio Direto, v.60, p.20-21, 2000.

SILVEIRA, P.M. da; STONE, L.F.; SILVA, J.G. da. Manejo da água de irrigação. In: SILVEIRA, P.M. da; STONE, L.F. (Ed.). Irrigação do feijoeiro. Santo Antônio de Goiás: Embrapa Arroz e Feijão, 2001. p.139-169.

TOMITA, C.K.; CAETANO, J.O.; CAFÉ-FILHO, A.C. Dano associado ao gênero Fusarium como patógeno radicular das culturas de feijão e soja nos Cerrados. In: SIMPÓSIO SOBRE O CERRADO, 8., INTERNATIONAL SYMPOSIUM ON TROPICAL SAVANNAS, 1., 1996, Brasília, DF. Biodiversidade e produção sustentável de alimentos e fibras nos Cerrados. Planaltina: Embrapa CPAC, 1996. p.263-267.

TORMENA, C.A.; ROLOFF, G.; SÁ, J.C.M. Propriedades físicas do solo sob plantio direto influenciadas por calagem, preparo inicial e tráfego. Revista Brasileira de Ciência do Solo, v.22, p.301-309, 1998.

TORRES, J.L.R.; PEREIRA, M.G.; FABIAN, A.J. Produção de fitomassa por plantas de cobertura e mineralização de seus resíduos em plantio direto. Pesquisa Agropecuária Brasileira, v.43, p.421-428, 2008.

WEINHOLD, A.R. Population of Rhizoctonia solani in agricultural soils determined by a screening procedure. Phytopathology, v.67, p.566-569, 1977.

ZAMBOLIM, L.; CASA, R.T.; REIS, E.M. Sistema plantio direto e doenças em plantas. Fitopatologia Brasileira, v.25, p.585-595, 2000.

ZIMMERMANN, F.J.P. Estatística aplicada à pesquisa agrícola. Santo Antônio de Goiás: Embrapa Arroz e Feijão, 2004. 402p. 